\title{
Tähelepanekuid soome ja eesti keele liitnimisõnadest
}

\author{
REET KASIK \\ Helsingi Ülikool, Tartu Ülikool
}

Ülevaade. Artiklis võrreldakse soome ja eesti keele liitsõnamoodustuse võimalusi. Grammatikatele toetudes tuuakse välja kummagi keele liitnimisõnade põhimallid ja vaadeldakse nende rakendamist tekstimoodustuses. Analüüsimaterjaliks on ajalehe Helsingin Sanomat ühe nädala pealkirjades kasutatud liitnimisõnad ja nende eesti keelde tõlkimise võimalused. Kirjeldatakse reeglipärasusi ja piiranguid, mis eesti liitsõnamoodustust soome omast eristavad.

Võtmesõnad: kontrastiivne keeleuurimine; liitsõnamoodustus; soome ja eesti keele kõrvutav grammatika; ajakirjanduskeel

\section{Sissejuhatus}

Lähedaste sugulaskeeltena on soome ja eesti keele grammatiline süsteem suhteliselt sarnane. Kummaski keeles on ulatuslik morfoloogia ning rikkalik ja paindlik derivatsioonisüsteem. Levinumad sõnamoodustusviisid nii eesti kui ka soome keeles on liitsõnade moodustamine ja sõnade tuletamine liidete abil. Süsteemi eri osades ja rakendustes on siiski tuntavaid erinevusi. Soome keele grammatiline vormistik ja morfoloogiliste reeglite süsteem on komplitseeritum kui eesti keeles. Paljudes võrdlevates uurimustes on tulnud esile soome tuletiste ja liitsõnade moodustamise paindlikkus ja suurem potentsiaal eesti keelega võrreldes. Olen varemgi, seoses eesti ja soome verbituletuse võrdlusega, pööranud 
tähelepanu soome keele polüsünteetilisusele: ühe sõnavormiga võib edasi anda terve eesti lause jagu infot: luetuttaa - paneb läbi lugema, laseb läbi lugeda; hukuttautuu - uputab ennast ära (Kasik 1989, 1997). Samasuunalisi tähelepanekuid on teinud Helle Metslang, laiendades kõrvutusi sõnatuletusest väljapoole. Tema toob näiteid possessiivsufiksitega infiniitsete verbivormide kasutamisest ja viitab mõningate näidetega ka soome keele väga lihtsalt rakendatavale liitsõnamoodustusele (sm keskivertolukija - ee keskmine lugeja, sm pullakahvit - ee kohv ja sai). Tarbekeel võib selle soome keele eripära innukal ärakasutamisel väga kaugele minna, tootes selliseid maratonsõnu nagu asiakastyytyväisyyskysely või aikuiskoulutussuunnitelma, mille edasiandmiseks eesti keeles läheb vaja süntaktiliselt seotud fraasi - küsitlus klientide rahulolu kohta, täiskasvanute koolitamise kava. Sellised sõnad moodustuvad deverbaalnoomeni ümber ja kujutavad endast seega ühe või mitme lause nominalisatsiooni, kirjutab Helle Metslang (1994: 201-202). Samas, kui eesti ja soome keele tuletussüsteemist, eriti verbituletistest on mingi võrdlev pilt olemas (Kasik 1989, 1991, 1997, 1998), siis liitsõnamoodustust pole minu teada soome ja eesti keeles keegi korralikumalt võrrelnud.

\section{Liitsõnade moodustusmallid}

Siinse artikli uurimismaterjaliks on liitnimisõnad ajalehe Helsingin Sanomat pealkirjades 18.-23.02.2008. Ajaleheuudiste pealkirjade iseärasus igasuguste muude pealkirjadega võrreldes on see, et uudise pealkiri on funktsionaalne - see peab lühidalt ja kompaktselt ära ütlema uudise enda, selle keskse sõnumi. Kuidas suruda sõnum kokku ühe-kaherealiseks pealkirjaks, kus oleks võimalikult palju infot - see kujutab endast teksti tihendamise ülesannet. Ja siin pakub soome keele grammatika mitmeid paindlikke võimalusi, mida eesti keele grammatikas ei ole ja mille hulgas liitsõnamoodustusel näib olevat oluline koht. Siinse analüüsi eesmärgiks on vaadata, millised on soome liitsõnade moodustusmallid ja kas on võimalik leida mingeid reeglipärasusi ja piiranguid, mis ei võimalda kõiki soome liitsõnamalle eesti keeles rakendada. 
Soome ja eesti keele liitsõnamoodustuse põhimallid ning viited ülevaate aluseks olevatele uurimustele on esitatud kummagi keele kirjeldavas grammatikas (ISK, EKG). Põhimõtteliselt moodustatakse liitnimisõnu eesti ja soome keeles sarnaste mallide järgi: täiendsõnaks on kõige sagedamini substantiiv ainsuse nominatiivis (lillkapsas, põõsasaed; kukkakaali, pensasaita) või genitiivis (laualamp, raamatukapp; kunnanjohtaja, äidinkieli), harvem mõnes muus vormis või mõni muu sõnaliik (vettehüpe, peataolek, tööleminek, heakskiit, magustoit, teisitimõtleja; maahanmuutto, voimassaolo, vesillelasku, isoäiti, puhtaanapito, hyvinvointi). Täiendsõna võib olla ka mitmuse genitiivis (lastearst, naisterätsep, käterätik, vanadekodu; lastentarha, kasvojenhoito, jäidenlähtö), kuigi sagedamini on ka mitmuslik täiendsõna ainsuse vormis (kartulikott, raamatukapp; housukangas, kirjahylly). (EKG: 458-459; ISK: 404-405.) Eesti ne- ja soome nen-liitelised täiendsõnad liituvad enamasti lühenenud s-tüvelistena (saabumisaeg, ühiselamu; saapumisaika, ruotsalaistutkija). (EKG: 465; ISK: 402.) Kummaski keeles on nii leksikaliseerunud, st sõnastikes esitatavaid liitsõnu kui ka tekstisidusaid juhuliitsõnu, mille moodustamine ja tähendus on motiveeritud otse eelneva kontekstiga. Eesti keele grammatikas pole tekstisidusale liitsõnamoodustusele eraldi tähelepanu pööratud, soome keele grammatikas on seda käsitletud põhjalikumalt (ISK: 396-398).

Eesti ja soome liitsõnamoodustuse erinevus tuleb esile mallide rakenduses. Soome keele liitnimisõnades on täiendosa tavaliselt ainsuse nominatiivis. Nominatiivne täiendsõna on üldisema tähendusega kui muud vormid. Nominatiivse täiendsõnaga liitsõnad on lahtine rühm, ja ajutised, st tekstisidusad uusmoodustised on üldjuhul just sellise struktuuriga. (ISK: 397-398.) Nominatiivse täiendsõna vahekord põhisõnaga on morfoloogiliselt spetsifitseerimata ja samal täiendsõnalgi võib eri põhisõnadega seoses olla erinevaid semantilisi funktsioone:pöytälamppu on harilikult laua peal, pöytälaatikko aga laua sees, pöytälevy moodustab laua pinna, pöytävuori iseloomustab mäe kuju, pöytätennis on mäng, mida mängitakse laual, pöytähopeat ja pöytätavat seostuvad söögilauaga, sõnas pöytäkirja on seos lauaga läbipaistmatu. Täiendsõna tähistab 
põhisõna korrelaadiga mingil viisil seotud või seda iseloomustavat seika. Genitiivse täiendsõnaga liitsõnad on morfoloogiliselt ja funktsionaalselt motiveeritud, nominatiivse täiendsõna ja tema põhisõna tähendusvahekord on lahtine, assotsiatiivne ja individuaalne. See puudutab nii leksikaliseerunud kui ka tekstisidusaid liitnimisõnu. Nominatiivse täiendsõnaga liitsubstantiivid on sageli kinnistunud teatud tähenduses, kuigi ka mõni teine tähendus oleks võimalik, vrd henkilöauto, kehyskertomus, kettutyttö, kuningasajatus, pussikalja. Teiselt poolt võivad nominatiivse täiendsõnaga liitsõnad olla juhumoodustised, mille tähendus on tihedalt seotud kasutuskontekstiga: kontekst juhib võimalikest alternatiivsetest tõlgendustest õige valikuni. (ISK: 396-398, vt ka Seppänen 1981.)

Ka eesti keele grammatikas esitatakse, et moodustusosade tähendusseos võib olla liitsõnas vormiliselt väljendatud (eksplitsiitne), st morfeemi või täiendosa tüvekuju abil esile toodud (riisipuder, tööleminek), aga kui täiendsõna on nominatiivis, siis jääb seos vormiliselt väljendamata, implitsiitseks (raudnael, ratastool, hammasratas). Eesti liitsõnades ei ole aga vormiline seotus EKG järgi otseses seoses tähenduse motiveeritusega. Grammatika järgi on nii nominatiivse kui genitiivse täiendosaga liitnimisõnad oma laadilt implitsiitsed ja võimaldavad väljendada mitmesuguseid semantilisi suhteid. Implitsiitsete liitsõnade sisu mõistmine põhineb ka genitiivse täiendsõna puhul kuulaja keelevälisel kogemusel: näiteks vorstikaupmees müüb vorsti, aga kaltsukaupmees ostab kaltsu kokku; lillemüüja täiendsõna tähistab müügiobjekti, tänavamüüja täiendsõna müügikohta, suvemüüja täiendsõna müügiaega. Enamasti on tegemist leksikaliseerunud tähendusega sõnadega. (EKG: 458-459.)

Täiendsõna vormi seos liitsõna tähendusega on eesti keeles üsna ebakindel. Kirjakeeles on püütud mõningal määral reeglistada nominatiivse ja genitiivse täiendsõna kasutamist, aga nagu Elli Riikoja uurimused on näidanud (Riikoja 1960), pole sellisel reeglistamisel selget rahvakeelset alust ja seetõttu on ka reeglistamispõhimõtted kirjakeeles kõikunud. Selgelt ülekaalus on eesti keeles siiski genitiivse täiendsõnaga liitnimisõnad ja ka kirjakeeles nominatiivse liitumise tüüpjuhtumitena esitatavates tähendusrühmades on rahvakeeles segakasutust (Riikoja 1956). 
Väliskujult on soome ja eesti keele liitsõnad sarnasemad kui moodustusmalli poolest: soome genitiiv on $n$-lõpuline ja kahe- või kolmesilbiline vokaaltüvi tähistab soome keeles nominatiivi, eesti keeles genitiivi (vrd sm kirjakieli, ee kirjakeel).

\section{Soome liitnimisõnade eestindamine}

\section{1. Ühesõnaline tõlkevaste}

Analüüsi aluseks oleva ajalehe Helsingin Sanomat ühe nädala pealkirjades oli kasutatud kokku 527 erinevat liitnimisõna. Püüdsin leida neile eestikeelsed vasted. Kui endale sobivat vastet meelde ei tulnud, kasutasin ka "Soome-eesti suursõnaraamatu" (SESS) abi. Enamikku otsitavatest sealt muidugi ei leidnud, sest tegemist oli nn tekstisõnadega, mõeldud pigem ühekordseks kasutamiseks, pigem grammatilised kui leksikaalsed moodustised. Neist 527-st 388 on tõlgitavad eesti keelde ühe sõnaga, mis moodustab umbes $73 \%$ neist liitsõnadest. Nende, n-ö leksikaalselt tõlgitavate liitsõnade hulgas võib tegelikult eristada mitu alarühma.

1. Üsna suure rühma moodustavad eesti ja soome keelele ühised (sama etümoloogiaga või laensuhtes) liitsõnad, kui liitumisviis ja reeglipärased häälikulised erinevused arvesse võtmata jätta: maailma maailm, umpisolmu - umbsõlm, lapsenlapsi - lapselaps, korkeakoulu kõrgkool, pääministeri - peaminister, olympiamitali - olümpiamedal, kulttuurikeskus - kultuurikeskus.

2. Soome liitsõnade hulgas on hulk selliseid, millele eesti keeles vastab lihtsõna. Enamasti on tegemist võõrsõnaga: maahanmuuttaja immigrant, liukuhihna - konveier, sarjakuva - koomiks, terveysasema polikliinik, vallankumous - revolutsioon, vaihtoehto - alternatiiv, tukikohta - baas, rikostutkija - kriminalist, väestönsiirto - evakuatsioon. Ühesõnalisi omasõnu on harvem, aga materjali hulgas leidus ka selliseid näiteid, kus soome liitsõnale vastab eesti keeles tuletis: arvosana - hinne, poissaolo - puudumine, matkanteko - reisimine. 
3. Kõige rohkem on selliseid näiteid, kus soome liitsõna on tõlgitav eesti keelde samuti liitsõnaga, kuigi etümoloogiliselt ei ole tegemist samade sõnadega. Moodustusmall võib üksikjuhtudel olla sarnane, mõlemas keeles nominatiivse täiendsõnaga (huippujohtaja - tippjuht, pikavippi - kiirlaen), aga enamasti on täiendsõna soome keeles nominatiivis, eesti keeles aga genitiivis (lomamökki - puhkemaja, pelikenttä - mänguväljak, palokunta - tuletõrje) või lühenenud tüvega (ulkoraja - välispiir, ulkomaalainen - välismaalane, joukkoliikenne - ühistransport, tarramuovi - kleepplast). Liitsõnalisi vasteid leidub ka pikematele kui kahesõnalistele liitsõnadele, kuigi eesti keel pikki liitsõnu eriti ei armasta. Siiski tundub loomulik kasutada eesti keeles soome keelega sarnaselt selliseid liitsõnu nagu ülikoolimaailm - yliopistomaailma, kalasuitsutusettevõte kalasavustamo, hiigelpilvelõhkuja - jättipilvenpiirtäjä, meretranspordiamet - merenkulkulaitos, edasikaebamisprotsess - valitusprosessi, transpordiosakond - kuljetussektori, autasustamispjedestaal - palkintopalli, majanduskurjategija - talousrikollinen. Vormiline tuletusmall on neiski sõnades sagedamini erinev kui sarnane.

4. Tõlgitav on ka suur osa verbaalse taustaga liitsõnadest, sest nominalisatsioonisüsteem on eesti ja soome keeles põhijoontes sarnane ja nii subjektiline kui ka objektiline täiendsõna võivad ühineda deverbaalnoomeniga liitsõnaks. Nagu eesti keeleski, on ka soomekeelse materjali hulgas rohkem objektilise täiendsõnaga deverbaale. Eesti keeles on objektiline täiendsõna genitiivis, soome keeles võib see olla nii genitiivis (presidentinvaalit - presidendivalimised, kannanotto - seisukohavõtt, ruoanjakelu - toidujagamine, metsänomistaja - metsaomanik), kui ka nominatiivis (lentokonevalmistaja - lennukiehitaja, broilerituotanto broileritoodang, jätekuljetus - jäätmevedu). ne-liiteline täiendsõna võib eesti keeles olla genitiivi kõrval ka s-tüveline (käyttörajoitus - kasutuspiirang, vaalivoitto - valimisvõit).

$d a$-infinitiivilise objektirektsiooniga verbidest on mõlemad verbid nominaliseeritud. Seegi on võimalik nii eesti kui ka soome keeles, aga soome keeles on deverbaalne täiendsõna nominatiivis, eesti keeles genitiivis või mine-tuletiste puhul s-tüveline: tappouhkaus - tapmisähvardus 
(vrd uhkaa tappaa - ähvardab tappa), ostopäätös - ostuotsus, myyntiaikeet - müügiplaanid, siirtoaikomus - kolimisplaan.

Subjektilise täiendsõnaga deverbaalseid liitsõnu leidub samuti kummaski keeles, siinse materjali hulgas nt kansanäänestys - rahvahääletus, junaliikenne - rongiliiklus, kansannousu - rahvaülestõus, luokkakokous klassikokkutulek, ilmastonmuutos - ilmastikumuutus, asuintilapalo eluasemepõleng. Selleski rühmas on soome liitsõnades täiendsõna kas nominatiivis või genitiivis, eesti keeles alati genitiivis.

Mõningal määral võivad ka adverbiaalsed laiendid kummaski keeles moodustada grammatiliselt väljendamata seosega liitsõnu (soome keeles nominatiivse, eesti keeles genitiivse täiendsõnaga), aga eesti keeles siiski piiratult (sellest pikemalt edaspidi): nettiriippuvuus - arvutisõltuvus (vrd riippua netista sõltuda arvutist), samuti pommi-isku - pommirünnak, puhelinpalvelu - telefoniteenus, itsemurhaisku - enesetapurünnak, ympäristövaikutus - keskkonnamõju, nousukiito-tõusukiirendus, vankilatuomio - vanglakaristus.

\subsection{Mitmesõnaline tõlkevaste}

Mida siis kujutab endast see veerand liitnimisõnadest, mida eesti keelde ei saa ühe sõnaga tõlkida? Enamik neist on muidugi nn tekstisõnad, teksti tihendamiseks kasutatavad süntaktilised moodustised. Aga mitte ainult.

1. Raskesti tõlgitavate liitsõnade hulgas on pärisliitsõnu, millele eesti keeles semantilistel või grammatilistel põhjustel liitsõnalist vastet moodustada ei saa. Semantilise põhjuse näiteks võiks tuua Helsingin Sanomate rubriigi nimetuse Vieraskynä. Omadus- ja nimisõna kokkukasvamine liitsõnaks ei ole eesti keeles massiline, aga mitte ka väga tavatu (suurriik, noormees, külmhoone jne). Adjektiiv võóras ise moodustab lühitüvelisena terve hulga liitsõnu: võõrkeel, võorriiik, võõrtööline jne. Aga siinses kontekstis ei tähenda soome vieras eesti võorrast, vaid külalist, liitsõna algusosana seega külalis-. Põhjuseks, miks vieraskynä ei saa vastuvõetaval viisil eesti keelde tõlkida, on ka sõna kynä tähendus - 
sellele pole eesti keeles lühikest ja täpset vastet; kirjutusvahend on ise üsna kohmakas liitsõna ega võimalda edasimoodustust, metafoorselt kasutatav sulg on kitsama tähendusega ja ebamugavalt homonüümne: sulg : sule või sulg : sulu. Kas külalissulg annaks külalisele võimaluse kirjutada või takistaks seda? Semantilistel põhjustel on raske tõlkida ka sellist üsna tavalist igapäevasõna nagu bussivuoro. Eestikeelne vaste voor on üsna piiratud kasutusega ja minun vuoroni on eesti keeles pigem minu kord. Kord on aga nii mitmetähenduslik sõna, et bussikord ei ütle eestikeelsele lugejale kuigi palju. Ei leidnud bussivuoro'le muud vastet kui graafikujärgne buss, aga seda ei saa kasutada kaugeltki igas kontekstis, vrd Bussivuoroja vähennetään - Bussid hakkavad käima harvemini. Kuidas aga tõlkida eesti keelde sellist sõna nagu sankarijulkkis - julkkissõnale ei ole eestikeelset vastet ja tähenduselt kõige lähem väljendusviis oleks vist kuulus kangelane, mis kindlasti ei ole kasutatav kõigis kontekstides. Samasse rühma paigutaksin soome väga tavalise liitsõna toppatakki, analüüsitavas materjalis tuli ette kevyttoppatakki. Toppatakki on SESS-i järgi eesti keeles vatijope ja kevyttoppatakki siis kerge vatijope. Aga iga eestlasest emakeelekõneleja jaoks tähendab vatijope puhvaikat ja sel vatijopel on konnotatiivseid tähendusi, mis kuidagimoodi ei võimalda seda tänapäevase tavarõiva toppatakki neutraalseks vasteks pidada.

2. Grammatilistel põhjustel ei saa eesti keeles moodustada liitsõnu kohanimetuletistest, mis soome keeles on väga tavalised: ranskalaispolitikko - Prantsuse politik, brittiministeriö - Briti ministeerium, venäläiskopteri - Vene helikopter, ranskalaispankki - Prantsuse pank, ranskalaiskirjailija - Prantsuse kirjanik. Kui isikut tähistava sõna juurde kuuluv kohanime genitiiv ei tähista rahvust, vaid elukohta, siis jääb genitiiv väheütlevaks ja eesti keeles peab kasutama veel pikemat väljendust: helsinkiläisministeri - Helsingist pärit minister, haminalaispari - Haminast pärit abielupaar, imatralaismies - Imatral elav mees. Kui põhisõna ei tähista isikut, vaid kohta, siis sellist piirangut ei ole: pariisilaislähiö Pariisi linnaosa. Kui rahvuse nimetust märkiv lane-tuletis ei ole seotud kohanimega, siis liitsõnamoodustuseks eesti keeles takistust ei ole: mustalaiskerjäläiset - mustlaskerjused. 
3. Grammatilistel põhjustel on piiratud liitsõnade moodustamine liitsõnadest. Selle kohta oli juba ka eespool näiteid, näiteks kõneks olnud kevyttoppatakki. Omadussõna võib mingis ulatuses olla ka eesti keeles liitnimisõna täiendsõnaks, aga mitte siis, kui põhisõnaks pakutav nimisõna on ise liitsõna. Eesti liitsõnad on tavaliselt kaheosalised, pikemad liitsõnad on määratud struktuuriga või leksikaliseerunud. Kui soome liitsõna mõni komponentsõna tuleks eesti keelde tõlkida liitsõnaga, siis on enamasti tulemuseks lahkukirjutatav fraas: rekkajono - veoautode järjekord, bussikaista - busside sõidurida, iltavastaanotto - õhtune vastuvõtt, käräjäoikeus - alamastme kohus, journalistiliitto - ajakirjanike liit, pääkaupunkiseutu - pealinna piirkond, elinaikakerroin - eluea koefitsient, korkeakoululista - kõrgkoolide nimekiri. Siia rühma tuleks ilmselt paigutada ka selline sõna nagu avopuoliso. Avoliitto on eesti keeles ise kolmeosaline liitsõna vabaabielu, ka puoliso on liitsõna - abikaasa. Neid on liiga kohmakas kokku panna toimivaks liitsõnaks vabaabieluabikaasa. Eesti keeles ongi võetud kasutusele teistsuguse loogikaga moodustatud liitsõna elukaaslane.

4. Ka soome süntaktiliste liitsõnade (nominalisatsioonide) hulgas on selliseid, mida eesti keeles ei ole loomulik liitsõnaks kokku kirjutada: pesänhoitaja - pärandvara haldaja, rikostutkinta - kuriteo uurimine, asuntorakentaminen - elumajade ehitus, synninpäästö - pattude andeksandmine, uimahallivertailu - basseinide võrdlemine. Needki näited kinnitavad eespool öeldut, et pikemate kui kahest sõnast koosnevate liitsõnade moodustamine on eesti keeles piiratum kui soome keeles. Nagu leksikaalsete liitsõnade puhul, nii on ka grammatiliste ühendite kokkukirjutamine erandlik, kui üks komponentidest on liitsõna. Eesti keel eelistab sel juhul pigem lahkukirjutamist

5. Eesti keeles ei saa moodustada liitsõnu materjali tähistavatest tuletatud adjektiividest nagu kuldne sõrmus, raudne kang. Tuletusalune substantiiv on juba ise materjalitähendusega ja adjektiiviliide kaob: kuldsõrmus, raudkang. Tundub siiski, et selline sõnamoodustus on pigem leksikaalne kui grammatiline ja seda ei saa automaatselt rakendada: villavaatteet - villased riided. 
6. Süntaktilisele (lausepõhisele) liitsõnale pole võimalik leida eestikeelset liitsõnalist vastet siis, kui eesti ja soome keeles on verbil erinev rektsioon või soome liitsõna ei võta arvesse süntaktilist seost. Soome keeles kõlab üsna loomulikult pealkiri Pelastuslaitos toivoo tervettä järkeä eläinhälytyksiin, mis tähendab, et päästeamet soovitab enne järele mõtelda, kui kutsuda päästeamet välja loomi päästma, aga eesti keeles ei saa seda tegevust automaatselt nimetada loomahäireks või loomaväljakutseks - selline liitsõna ei ole tähenduselt piisavalt läbipaistev. Enamasti kõlab selliste liitsõnade vastena eesti keeles paremini verbirektsiooni säilitav mitmesõnaline fraas: veronkiertäjä - maksudest kõrvalehoidja, vankilennätys - vangide transport lennukiga, dopingkäry - dopinguga vahelejäämine, turvallisuusuhka - oht turvalisusele, jäsenäänestys - hääletamine ainult liikmetele, puheenjohtajakisa - võistlus esimehe koha pärast, kansanäänestysehdotus - ettepanek rahvahääletuseks, mestaruusjahti - jaht meistritiitlile, konkurents meistritiitli pärast.

7. Osa soome liitsõnu on sellised, et seal ei ole võimalik üheselt määrata täiendsõna ja põhisõna semantilist ega süntaktilist vahekorda, vaid tegemist on leksikaalse üksusega, millele lööva vaste leidmiseks oleks vaja Eesti omaaegse terminikorüfee Johannes Voldemar Veski kogemusi ja annet. Neist liitsõnadest, mida ei saa eesti keelde ühe sõnaga tõlkida, on üle 10\% selliseid, mida on raske heakõlaliselt tõlkida ka pikema nimisõnafraasiga, nagu näitavad järgmised üsna kohmakad tõlkekatsed:

kivijalkaravintolat 'elumajade esimestel korrustel paiknevad restoranid' korruptiokuulustelu 'ülekuulamine korruptsiooniga seoses' avustajaraha 'raha parlamendiliikmetele abiliste palkamiseks' talousrikosvangit 'majanduskuritegude eest vangi mõistetud kurjategijad' ihmisoikeuspomo 'inimõigustega tegeleva ametkonna juht' dopingilmianto 'pealekaebus dopingu tarvitamise kohta' syyteharkinta 'süüdistuse esitamise kaalumine'

Mis võiks olla eesti keeles teräväpiirtolähetys, kimppakyyti, liityntäpysäköinti? Või kuidas tõlkida eesti keelde järgmised pealkirjad: 
Credit Suisse pankki teki kahden miljardin alaskirjaukset

Postikorttikampanja vaatii lakia päästövähennyksistä

Puhemies Niinistö: Eduskunnan pitää uusia avustajakäytäntönsä

SM-liiga valmistelee uusia toimia katsomohäiriköinnin kitkemiseksi

\section{Kokkuvõte}

Ainestiku analüüsi põhjal võib järeldada, et eesti liitsõnamoodustus eeldab soome omast selgemat semantilist suhet täiendsõna ja põhisõna vahel. Tähendusseos peegeldub ka liitsõnavormistuses. Eesti ja soome liitsõnade põhimoodustusmall on fonoloogiliselt sarnane (vokaallõpulise täiendsõnaga), kuid morfoloogiliselt erinev. Soome liitsubstantiivide vokaallõpuline täiendsõna on üldjuhul nominatiivis, mis tähendab seda, et liitsubstantiivid on oma laadilt implitsiitsed. Neis jääb moodustusosade tähendusseos vormiliselt väljendamata, sest nominatiivivorm ei osuta mingis mõttes seosele. Sellise ehitusega nimetused võimaldavad väljendada väga mitmesuguseid semantilisi suhteid ja leksikaaltähendusi. Eesti liitnimisõnade täiendosis on valdavalt genitiivis. Genitiivivormi funktsioon on seose märkimine. Eesti liitsõnakirjeldus põhinebki semantilistel mallidel: genitiivis täiendsõna puhul on võimalik tõlgendada, millise semantilise tunnuse järgi täiendsõna põhisõna tähendust iseloomustab või kitsendab. Puhtalt grammatilise seosega adverbiaalseid rektsioonilisi laiendeid ei ole eesti keeles kerge liitsõna täiendsõnaks sobitada. 


\section{Kirjandus}

EKG = Erelt, Mati, Reet Kasik, Helle Metslang, Henno Rajandi, Kristiina Ross, Henn Saari, Kaja Tael, Silvi Vare 1995. Eesti keele grammatika I. Morfoloogia. Sõnamoodustus. Trükki toimetanud Mati Erelt (peatoimetajana), Tiiu Erelt, Henn Saari, Ülle Viks. Tallinn: Eesti Teaduste Akadeemia Keele ja Kirjanduse Instituut.

ISK = Hakulinen, Auli, Maria Vilkuna, Riitta Korhonen, Vesa Koivisto, Tarja-Riitta Heinonen, Irja Alho 2004. Iso suomen kielioppi. Suomalaisen Kirjallisuuden Seuran toimituksia 950. Helsinki: Suomalaisen Kirjallisuuden Seura.

Kasik, Reet 1989. Eestin ja suomen verbinjohto. - Sananjalka 31. Turku, 81-92.

Kasik, Reet 1991. Derivatiivsetest laenudest. $u$-liitelised verbid eesti ja soome keeles. - Keel ja Kirjandus 8, 466-476.

Kasik, Reet 1997. Typology of Estonian and Finnish word-formation. The Verb. Mati Erelt (Ed.). Estonian: Typological Studies II. Publications of the Department of Estonian of the University of Tartu 8. Tartu: TÜ Kirjastus, 42-73.

Kasik, Reet 1998. Viron line-suffiksilliset tekijännimet. - Oekeeta asijoo. Commentationes Fenno-Ugricae in honorem Seppo Suhonen. Suomalais-ugrilaisen Seuran toimituksia 228. Helsinki: Suomalais-ugrilainen Seura, 218-224.

Metslang, Helle 1994. Kielet ja kontrastit. - Virittäjä 2, 203-226.

Riikoja, Elli 1956. Kirjakeele ja rahva kõnekeele vahekorrast mõningates nominatiivse liitumise rühmades. - Eeva Ahven (Toim.). Keelelisi küsimusi. Eesti NSV Teaduste Akadeemia Keele ja Kirjanduse Instituudi uurimused I. Tallinn: Eesti Riiklik Kirjastus, 88-104.

Riikoja, Elli 1960. Eesti keele nimisõnade nominatiivse liitumise reeglite rahvakeelne alus. Kandidaadiväitekiri Tartu Ülikooli eesti keele õppetoolis.

Seppänen, Lauri 1981. Nominaalikompositumien semantiikkaa. - Sananmuodostuksen ongelmia. Seminaari Seilissä 3.-4.9.1981. Suomen kielitieteellisen yhdistyksen julkaisuja 7. Turku: Turun yliopisto, 69-82.

SESS = Soome-eesti suursõnaraamat. Suomi-viro suursanakirja I-II. Eesti Keele Instituut, Kotimaisten kielten tutkimuskeskus. Tallinn: Eesti Keele Instituut; Helsinki: Kotimaisten kielten tutkimuskeskus, 2003.

\section{Reet Kasik}

Tartu Ülikooli eesti ja üldkeeleteaduse instituut

Ülikooli 18

51014 Tartu, Estonia

reet.kasik@ut.ee 


\title{
Some notes on the Finnish and Estonian compound nouns
}

\author{
REET KASIK \\ University of Helsinki, University of Tartu
}

The article compares compound noun formation in Finnish and Estonian. On the basis of published grammars, the basic patterns of noun compounding are described. Their application in text is analysed on the material of the Finnish daily Helsingin Sanomat, examining the compound nouns used in the titles and their possible translations into Estonian. The regularities and restrictions behind the compounding differences between the two languages are pointed out.

Keywords: contrastive linguistics; compounding; contrastive grammar of Finnish and Estonian; media language 